\title{
Kernos
}

Revue internationale et pluridisciplinaire de religion grecque antique

$2 \mid 1989$

Varia

\section{Hommage à Georges Mylonas}

\section{Evanghelos A. Moutsopoulos}

URL : http://journals.openedition.org/kernos/230

DOI : $10.4000 /$ kernos.230

ISSN : 2034-7871

\section{Éditeur}

Centre international d'étude de la religion grecque antique

\section{Édition imprimée}

Date de publication : 1 janvier 1989

Pagination : 9-11

ISSN : 0776-3824

Référence électronique

Evanghelos A. Moutsopoulos, « Hommage à Georges Mylonas », Kernos [En ligne], 2 | 1989, mis en ligne le 02 mars 2011, consulté le 03 mai 2019. URL : http://journals.openedition.org/kernos/230 


\section{IN MEMORIAM GEORGES E. MYLONAS}

Le décès de Georges Mylonas, survenu à Athènes le 15 avril dernier, a privé la science de l'archéologie d'une figure d'envergure internationale. Plus qu'un érudit d'une valeur incomparable, il fut une personnalité marquante; et plus encore qu'une personnalité, il fut une personne au sens le plus authentique du terme. Le vide qu'il a laissé derrière lui sera, à coup sûr, difficile à combler pendant de longues années. Les universités américaines où Georges Mylonas a formé des générations entières de chercheurs, l'Académie d'Athènes, à l'éclat de l'activité de laquelle il a brillamment contribué, et surtout la Société Archéologique d'Athènes, dont il a été le Secrétaire général pendant de nombreuses années, garderont à jamais l'empreinte puissante de son passage. Le présent volume de Kernos est tout naturellement dédié à la mémoire de ce savant. Tékvov rvíoıov de l'Hellade, en qui le Centre d'Étude de la Religion Grecque Antique a perdu aussi son Président d'honneur.

Georges Mylonas était tout d'abord hellène avant de devenir un érudit de l'hellénisme. Né à Smyrne le 9 décembre 1898, il fait ses études primaires et secondaires à l'École Évangélique de Smyrne et au Collège américain de Paradeisos dans cette même ville, habitée à cette époque encore par quelque deux millions de Grecs. En 1919, il commence ses études universitaires à la Faculté de Philosophie de l'Université d'Athènes, mais il est mobilisé par l'Armée grecque à l'occasion de l'expédition d'Asie Mineure en 1920-1922. Fait prisonnier par l'armée adverse, Georges Mylonas restera dans une prison militaire jusqu'en avril 1923. Une fois libéré et rentré à Athènes, il est engagé par l'École Américaine d'Études Classiques comme assistant de l'architecte S. Thomson. Dès cette année-là, il prend part aux fouilles américaines à Corinthe, à Némée et à Aghiorghitika. En 1928, il assiste D.M. Robinson aux fouilles d'Olynthe et étudie les vestiges néolithiques de la ville qu'il publie dans le premier volume de la série Excavations at Olynthus (Baltimore, 1929). C'est aussi durant cette première période de sa carrière que Georges Mylonas est proclamé Docteur en Philosophie et Lettres de l'Université d'Athènes. 1928 marque également son départ pour les ÉtatsUnis où il séjournera durant plusieurs décennies.

Aux États-Unis, Georges Mylonas enseigne l'archéologie dans maintes universités aussi fameuses que celles de Chicago, de l'Illinois, du Missouri, de Saint-Louis, etc. Parallèlement, il veille à sensibiliser l'opinion publique américaine au passé purement hellénique de la Macédoine. En 1968, il entreprend une longue tournée scientifique de par le monde, au cours de 


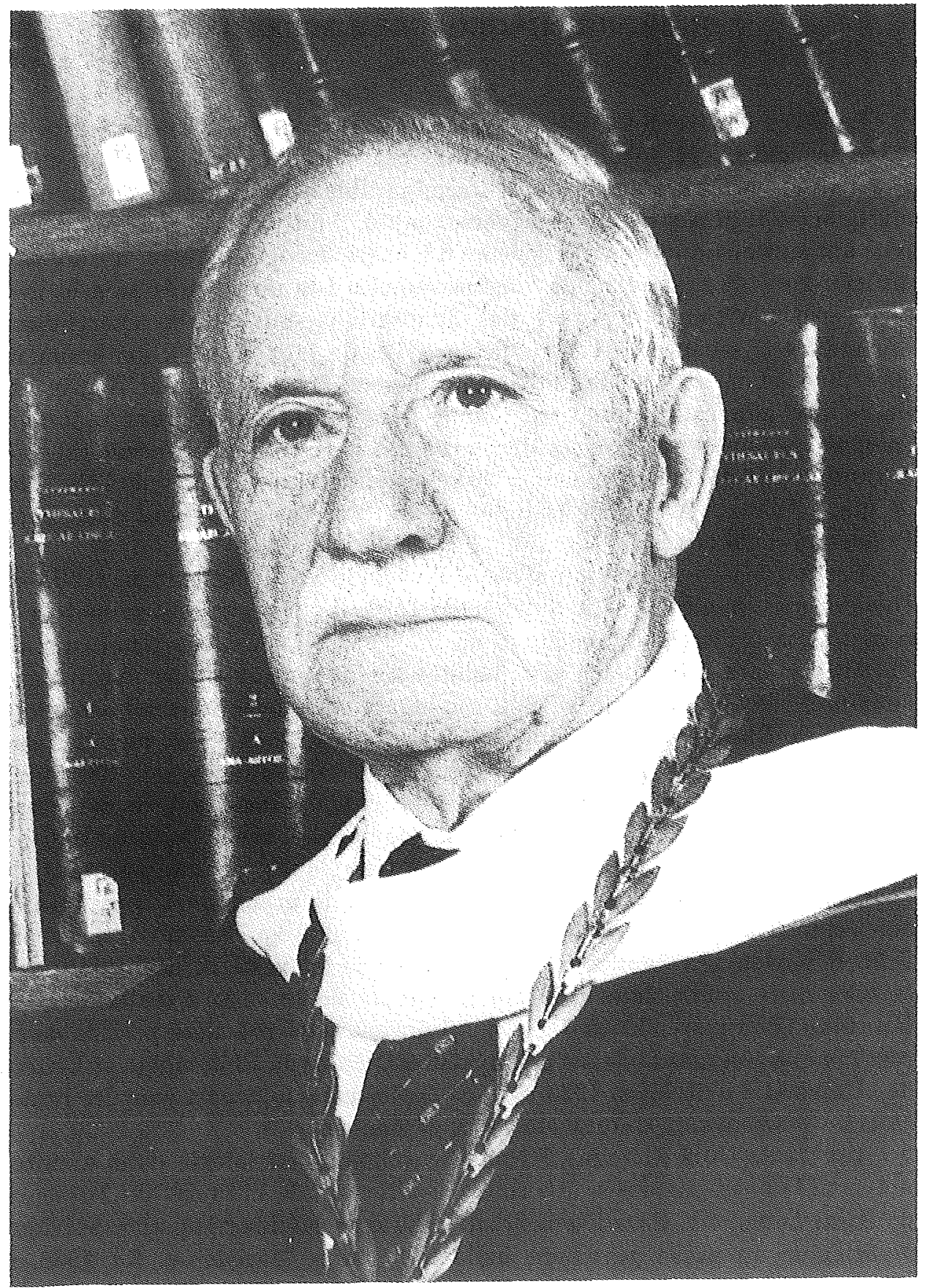


laquelle il donne un grand nombre de conférences sur l'archéologie et l'histoire de la Grèce, dans différentes universités d'Australie, de Nouvelle Zélande, du Japon et d'Afrique du Sud.

Cette même année, déjà tenant du titre de Distinguished University Professor in the Humanities de la Washington University of St-Louis et de celui de Professeur honoris causa de l'Université d'Athènes, Georges Mylonas rentre en Grèce pour s'y établir définitivement. Membre actif (depuis 1969) de l'Académie d'Athènes — qu'il a été appelé à présider en 1980 —, il est également élu, en 1969, membre du Conseil d'Administration de la Société Archéologique d'Athènes, et dès 1979 il devient le Secrétaire général de cette vénérable institution, responsabilité qu'il assumait encore en avril dernier. Quelques mois avant son décès inattendu, le Conseil d'Administration du Centre d'Étude de la Religion Grecque Antique l'élisait Président d'honneur à l'unanimité.

Parmi les innombrables fouilles auxquelles Georges Mylonas a participé et parmi ses nombreuses publications, celles qui concernent la recherche dans le domaine de la religion grecque antique jouissent d'une autorité particulière. Fouilleur d'Éleusis depuis 1930, il a publié un nombre important d'études sur les vestiges matériels et sur les mystères antiques des divinités du site. Son ouvrage Eleusis and the Eleusinian Mysteries paru en 1964 aux presses de la Princeton University, et tant de fois réimprimé depuis lors - ce qui en confirme le succès -, constitue l'instrument scientifique fondamental pour l'étude de ce centre cultuel si réputé dès l'antiquité. Les fouilles que Georges Mylonas a conduites à Mycènes et qui lui ont valu d'être appelé le digne héritier de Schliemann ont mis au jour le centre cultuel qui a été

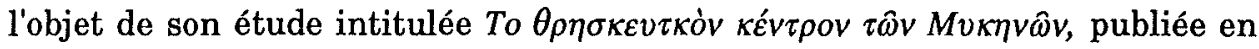
1972 aux éditions de l'Académie d'Athènes, sous le $n^{\circ} 33$. Quelques années après, Georges Mylonas dotait la recherche dans le domaine de la religion grecque d'un autre instrument de grande valeur, inspiré lui aussi par

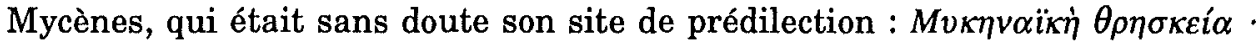
$v \alpha o i, \beta \omega \mu o i, \kappa \alpha l \tau \varepsilon \mu \varepsilon ́ v \eta$, paru en 1977 aux éditions de l'Académie d'Athènes sous le $n^{\circ} 39$.

À Mycènes, Georges Mylonas a réalisé une part très importante de son œuvre, dont la dernière manifestation d'éclat est le nouveau musée, digne du passé des lieux, dont il veilla à pourvoir le site. Désormais, à Mycènes aussi, auprès des sépultures royales mycéniennes, repose en paix cette sommité de l'archéologie grecque.

Évanghélos MOUTSOPOULOS

Membre de l'Académie d'Athènes Président du C.E.R.G.A. 